\title{
The Convergence of Regional House Price: An Application to Taiwan
}

\author{
Mei-Se, Chien ${ }^{a, *}$, Shu-Jung, Chang Lee ${ }^{b}$ \\ ${ }^{a}$ Department of Finance, National Kaohsiung \\ University of Applied Sciences \\ ${ }^{b}$ Department of Logistics Engineering and Management, \\ National Taichung Institute of Technology
}

\begin{abstract}
The notion of a ripple effect in the housing market implies stationarity in regional:national house price ratios. The central aim of this study is to investigate whether the ripple effect exists in Taiwan's regional house price ratio by implementing the Breuer et al. (2001) Panel SURADF unit root tests, which can improve upon the less efficient estimations of conventional unit root tests. The Panel SURADF tests a separate unit-root null hypothesis for each individual panel member and therefore identifies how many and which series in the panel are stationary processes. We do find that the house price ripple effect in Taiwan holds true for two of five regions by the Panel SURADF tests.
\end{abstract}

Keywords: Regional house price, ripple effect, panel SURADF tests

\section{Introduction}

The behavior of house prices has received much attention in the economics and financial literature. While some papers have examined whether the upswing in house prices have caused bubbles in individual housing markets (Cook, 2005), others have used asset pricing models to investigate house prices and the differences between housing and other financial assets (Weeken, 2004). However, some previous house price studies have referred to the ripple effect for different regional house prices, which refers to the phenomenon whereby the price changes in an area and later spreads to other regions.

Some studies support that the notion exists of a causal link between different regional prices for houses, using cross-correlation matrices and Granger causality tests (Gussani \& Hadjimatheou, 1991; MacDonald and Taylor, 1993; Alexander and Barrow, 1994; Berg, 2002). In comparison with the results of the above studies, Ashworth and Parker (1997) cast doubt on the ripple hypothesis using the ECM model and the Lagrange multiplier test (attributed by Anselin and Hudak, 1992, to Burridge, 1980).

As Meen (1999) indicates, the ripple effect implies a long-run constancy, or stationarity, in the ratio of house prices in different regions to the national figure. Meen (1999) fails to reveal significant evidence of stationarity in the regional: national house price ratios for the UK after applying the ADF (of Dickey and Fuller, 1979) unit root test. Cook (2003) proposes an asymmetric unit root test, the MTAR test of Newbold et al. (2001), to re-examine the stationarity of regional house price ratios. In contrast to the results of Meen (1999), the application of this alternative approach results in the detection of overwhelming convergence, or stationarity, in a number of regions of the UK. It suggests that the failure of Meen (1999) to uncover convergence is due to an underlying asymmetry in the adjustment process being ignored.

Cook (2005) detects stationarity by an alternative method which involves the joint application of two tests, rather than following the approach of Meen (1999) who uses the ADF unit root test. The two tests in question are the DF-GLS test (of Elliott et al., 1996) and the stationarity test of KPSS (of Kwiatkowski et al., 1992). This approach, a joint application of unit root and stationarity tests, has been employed as confirmatory analysis for it makes the non-rejection by one test be 'confirmed' by rejection after applying the other test. Importantly, it is found that in comparison to previously considered joint testing approaches and individual unit root tests, the proposed method effectively decreases the frequency with which stationary series are mistakenly concluded to be a unit root. The results of Cook (2005) provide supportive evidence of stationarity in regional house price ratios as implied by the ripple effect of the UK.

It has been recently found that conventional unit root tests have lower power with the near-unit-root, but are stationary alternatives. Even more than that, numerous studies have indicated that conventional unit root tests have failed to consider information across regions, therefore yielding less efficient estimations

\footnotetext{
* Corresponding author. E-mail addresses: cms@cc.kuas.edu.tw (Mei-Se, Chien)
} 
(Chang et al, 2005). For the above factors, it is worth it to re-examine previous studies of a unit root in the ripple effect.

A recently proposed approach to increase power in testing for a unit root involves the use of panel data, because panel data can provide much more information than either cross-section or time series data and considering the power of an individual unit root test. Levin \& Lin (1992) and Im et al. (1997) develop the asymptotic theory and the finite-sample properties of ADF tests of panel data, and both show that even relatively small panels can improve power in testing for a unit root. Taylor and Sarno (1998) and Breuer et al., (2001) demonstrate that the recent methodological refinements of the Levin and Lin test fail to fully address the 'all-or-nothing' nature of the test. Taylor and Sarno (1998) propose tests that allow the autoregressive parameters to differ across panel members under the stationary alternative, but because they are joint tests of the null hypothesis, they are not informative to judge the number of stationary series under the case of rejecting the null hypothesis.

Breuer et al. (2001) further illustrate that, just as with a simple regression, it does not mean that each coefficient is non-zero when an F-statistic rejects the null that a vector of coefficients is equal to zero. Likewise, if the unit-root null hypothesis is rejected, then it may be wrong to infer that all series in the panel are stationary. To solve the problem, Breuer et al. (2001) employ the seemingly unrelated regressions augmented Dickey-Fuller (SURADF) test, which is an augmented Dickey-Fuller test based on the panel estimation method of seemingly unrelated regression (SUR). In comparison with the MADF test of Taylor and Sarno (1998), they use separate null and alternative hypotheses to test for each panel within a SUR framework.

Previous studies about the ripple effect are unfortunately blurry at the present time. This paper will show whether applying an alternative, improved testing methodology, the Breuer et al. (2001) Panel SURADF unit root tests, results in the expected convergence being detected. Furthermore, the ripple effect hypothesis has not been done previously for Taiwan, but has been published for other countries. The central aim of this study investigates whether the ripple effect exists in Taiwan's regional house price ratios by using the Breuer et al. (2001) Panel SURADF unit root tests. This paper proceeds as follows. Section 2 discusses the ripple effect, Section 3 describes the methodology, Section 4 presents the empirical findings, and in Section 5 some conclusions are drawn.

\section{The Ripple Effect}

Regional trends for house prices are interesting for many reasons. British studies have shown that price changes on the house market start in the South East and later spread to other regions. This phenomenon is called the ripple effect. If it is possible to illustrate that house prices in different regions may diverge in the short run, then a long-run equilibrium exists. However, Meen (1999) notes while much statistical evidence has been presented involving the ripple effect, research studies offer little in the form of convincing theoretical explanation. Meen (1999) suggests that the ripple effects could be caused by four factors: migration, equity transfer, spatial arbitrage, and spatial patterns in the determinants of house prices.

If a ripple effect indeed exists, then it will be predicated on a degree of long-run relative constancy between regional house prices where the ratio between each regional price and the national house price is stationary (Meen, 1999; Cook, 2003.2005). This stationarity results from the assumption under the ripple effect of a steady regional spillover of changes in house prices. Previous studies about the ripple effect are unfortunately blurry at the present time. This paper will show, though, whether applying an alternative, improved testing methodology, the Breuer et al. (2001) Panel SURADF unit root tests, results in the expected convergence being detected.

\section{Panel Unit Root Methodology}

Breuer et at. (2001) demonstrate that if the unitroot null hypothesis is rejected, then it may be wrong to infer that all series in the panel are stationary. To solve the problem, Breuer et al. (2001) employ the seemingly unrelated regressions augmented DickeyFuller (SURADF) test, which is an augmented Dickey-Fuller test based on the panel estimation method of seemingly unrelated regression (SUR). Differing from the MADF test of Taylor and Sarno (1998), Breuer et al. use separate null and alternative hypotheses to test for each panel within a SUR framework. The conventional ADF test is based on the following equations:

$$
\begin{gathered}
\Delta Y_{1, t}=\alpha_{1}+\beta_{1} Y_{1, t-1}+\sum_{i=1}^{1} \gamma_{1, i} \Delta X_{1, t-i}+\theta t+\varepsilon_{1, t} \\
t=1,2, \ldots, T \\
\begin{array}{c}
\Delta Y_{2, t}=\alpha 2+\beta_{2} Y_{2, t-1}+\sum_{i=1}^{2} \gamma_{2, i} \Delta X_{2, t-i}+\theta t+\varepsilon_{2, t} \\
t=1,2, \ldots, T
\end{array} \\
-\quad \begin{array}{c}
\Delta Y_{N, t}=\alpha_{N}+\beta_{N} Y_{N, t-1}+\sum_{i=1}^{N} \gamma_{N, i} \Delta X_{N, t-i}+\theta t_{t+1}+\varepsilon_{N, t} \\
t=1,2, \ldots, T(1)
\end{array}
\end{gathered}
$$

The $N$ null and alternative hypotheses are tested individually: 


$$
\begin{gathered}
H_{0}^{1}: \beta_{1}=0 ; H_{A}^{1}: \beta_{1}<0 \\
H_{0}^{2}: \beta_{2}=0 ; H_{A}^{2}: \beta_{2}<0 \\
\quad \cdot . \cdot \\
H_{0}^{N}: \beta_{N}=0 ; H_{A}^{N}: \beta_{N}<0,
\end{gathered}
$$

with test statistics computed from the SUR estimates of system (1). As Breuer et al. (2001) present that the restriction of an identical lag length across panel members could bias test statistics, we select the lag length for each equation using Perron's (1989) method.

In contrast to other panel unit tests such as the MADF test of Taylor and Sarno (1998), Breuer et al. (2001) suggest an alternative null hypothesis to derive the SURADF tests. While the others are joint tests of a unit root for all members of the panel, the Panel SURADF tests a separate unit-root null hypothesis for each individual panel member and hence judges how many and which series in the panel are stationary processes. However, by analogy to the MADF test of Taylor and Sarno (1998), this test also has nonstandard distributions and the critical values must be achieved by simulations.

\section{Empirical Results}

This empirical work employs the regional:national house price ratios for five regions of Taiwan - namely, Taipei city, Taipei county, Taoyuan-Hsinchu, Taichung, and Tainan-Kaohsiung - over the period 1983Q1 to 2005Q3. The regional/national house price ratios are created by subtracting the natural logarithm of the aggregate figure of Taiwan's house prices from the natural logarithm of the house prices for a given region. The data are drawn from the housing index database of Cathay Real Estate Development Comapny.

For comparison, we apply the same conventional unit root tests of Cook (2005), including ADF, DFGLS (of Elliott et al., 1996) and KPSS tests, to detect stationarity of the regional/national house price ratios of each region. The lag order of the test is selected on the basis of the Perron (1989) recursive t-statistic. The results of applying the ADF, DF-GLS, and KPSS unit root tests at the $5 \%$ level of significance are presented in Table 1 . The results in Table 1 clearly indicate that the ADF test fails to reject the null of non-stationary regional/national house price ratios for Taipei city, Taipei county and Tainan-Kaohsiung at the 5\% level of significance. The result of the KPSS test is the same. The result for the ADF and KPSS joint testing of Cook (2005) also supports the above results. Turning to the result for the DF-GLS test, accepting the null of non stationary occurs for two regions (Taoyuan -Hsinchu, Taichung), which is confirmed by the joint testing of DF-GLS and KPSS of Cook (2005). Therefore, these empirical results of conventional unit root tests are presented to support the ripple effect in two or three of the five regions. The empirical result of Taipei county is inconsistent by different tests.

Numerous studies have recently indicated that conventional unit root tests have failed to consider information across regions, therefore yielding less efficient estimations, which could cause the inconsistent results for Taipei county. To improve the above phenomenon, we apply the Breuer et al. (2001) panel-based unit root test. Table 2 shows Breuer et al.'s (2001) panel SURADF test results. Table 2 also reports the estimated 5\% critical values, obtained from simulations based on 51 observations for each series and 10,000 replications using the lag and covariance structure from the panel of regional:national house price ratios series, for each of the five panel members. Considering the results for Breuer et al.'s (2001) panel SURADF test, a rejection of the unit root hypothesis occurs for Taoyuan-Hsinchu and Taichung regions at the $5 \%$ level of significance. This certainly presents that the house price ripple effect exists just for Taoyuan-Hsinchu and Taichung, but not for Taipei county.

Table 1. Univariate unit root tests

\begin{tabular}{|l|l|l|l|}
\hline \multicolumn{1}{|c|}{ Regionname } & \multicolumn{1}{c|}{ ADF } & \multicolumn{1}{c|}{ DF-GLS } & \multicolumn{1}{c|}{ KPSS } \\
\hline TaipeiCity & $-2.66(0)$ & $-1.59(0)$ & $0.406^{* *}(5)$ \\
\hline Taipei County & $-1.94(0)$ & $-1.95^{* *}(0)$ & $0.375^{* *}(5)$ \\
\hline Taoyuan-Hsinchu & $-4.172^{* *}(0)$ & $-3.196^{* *}(0)$ & $0.188(4)$ \\
\hline Taichung & $-4.228^{* *}(0)$ & $-3.672^{* *}(0)$ & $0.391(3)$ \\
\hline Tainan-Kaohsiung & $-1.732(0)$ & $-1.107(0)$ & $0.844^{* *}(5)$ \\
\hline
\end{tabular}
Notes: ** indicates significance at the 0.05 level. The number in
brackets indicates the lag truncation for the Bartlett Kernel, as
suggested by the Newey-West test (1987). The number in
parentheses indicates the lag order selected based on the recursive t-
statistic, as suggested by Perron (1987).

Table 2. SURADF tests and critical values

\begin{tabular}{|l|l|l|}
\hline \multicolumn{1}{|c|}{ Region name } & SURADF & $\begin{array}{l}5 \% \text { critical } \\
\text { Values }\end{array}$ \\
\hline Taipei City & -1.861 & -3.202 \\
\hline Taipei County & -2.135 & -2.986 \\
\hline Taoyuan-Hsinchu & $-3.789^{* * *}$ & -3.064 \\
\hline Taichung & $-4.149^{* * *}$ & -2.967 \\
\hline Tainan-Kaohsiung & -1.241 & -3.041 \\
\hline
\end{tabular}

The empirical results of conventional unit root tests support the ripple effects in two or three of the five regions by different tests. We clearly confirm the house price ripple effect in Taiwan holds true for two of the five regions after applying the Breuer et al. (2001) Panel SURADF unit root tests.

\section{Conclusions}

The hypothesis of a ripple effect in Taiwan's regional house prices ratios is examined by Breuer et al. (2001) Panel SURADF unit root tests, which can 
improve upon the less efficient estimations of conventional unit root tests. The Panel SURADF tests a separate unit-root null hypothesis for each individual panel member and therefore identifies how many and which series in the panel are stationary processes. The empirical results of conventional unit root tests are presented to support the ripple effect in two or three of the five regions by different tests. Furthermore, we clearly confirm that the house price ripple effect in Taiwan holds true for two of five regions by the Breuer et al. (2001) Panel SURADF unit root tests.

\section{References}

[1] Alexander, C. and M. Barrow, "Seasonality and cointegration of regional house prices in the UK," Urban Studies, 31, pp.1667-1689, 1994.

[2] Anselin, L. and S. Hudak, "Spatial econometrics in practice," Regional Science and Urban Economics, 22, pp.500-536, 1988.

[3] Ashworth, J. and S. Parker, "Modelling regional house prices in the UK," Scottish Journal of Political Economy, 44, pp.225-246, 1997.

[4] Berg, L., "Prices on the second-hand market for Swedish family houses: correlation, causation and determinants," European Journal of Housing Policy, 2(1), pp.1-24, 2002.

[5] Breuer, J. B., R. Mcnown, and M. S. WALLACE, "Misleading inferences from panel unit-root tests with an illustration from purchasing power parity," Review of International Economics, 9(3), pp.482- 493, 2001.

[6] Burridge, P., "On the Cliff-Ord test of spatial correlation," Journal of the Royal Statistical Society, Series B, 42, pp.107-108, 1980.

[7] Chang, T., K. C. Lee, C. C. NIEH, and C. C. WEI, "An empirical note on testing hysteresis in unemployment for ten European countries: panel SURADF approach," Applied Economics Letters, 12, pp.881-886, 2005.

[8] Cook, S., "The convergence of regional house prices in the UK," Urban Studies, 40(11), pp.2285-2294, 2003.

[9] Cook, S., "Regional house price behaviour in the UK: application of a joint testing procedure," Physica A 345, pp.611-621, 2005.

[10] Dickey, D. and W. Fuller, "Distribution of the estimators for autoregressive time series with a unit root," Journal of the American Statistical Association, 74, pp.427-431, 1979.

[11] Elliott, G., T. J Rothenberg, and J. H. Stock, "Efficient tests for an autoregressive unit root," Economic Record, 77, pp.252-269, 1996.

[12] Guisanni, B. and G. Hadjimathou, "Modelling regional house prices in the United Kingdom,"
Papers in Regional Science, 70, pp.201-219, 1991.

[13] Im, K. S., M. H. Pesaran, and Y. Shin, Testing for unit roots in heterogeneous panels, DAE Working Papers 9526, University of Cambridge, 1997.

[14] Kwiatkowoski, D., P. Phillips, P. Chmidt, and J. Shin, "Testing the null hypothesis of stationarity against the alternative of a unit root," Journal of Econometrics, 54(1-3), pp.159-178, 1992.

[15] Levin, A. and C. F. Lin, Unit root in panel data: asymptotic and finite-sample properties, Discussion Paper No. 93-56, Department of Economics, University of California, San Diego, 1992.

[16] MacDonald, R. and M. Taylor, "Regional house prices in Britain: long-run relationships and short-run dynamics," Scottish Journal of Political Economy, 40, pp.43-55, 1993.

[17] Meen, G. "Regional house prices and the ripple effect: a new interpretation," Housing Studies, 14, pp.733-753, 1999.

[18] Newbold, P., S. Leybourne, and M. Wohar, "Trend-stationarity, difference-stationarity or neither: further diagnostic tests with an application to U.S. real GNP, 1875-1993," Journal of Economics and Business, 53, pp.85$102,2001$.

[19] Newey, W. and K. West, "A simple, positive semi-definite, heteroskedasticity and autocorrelation consistent covariance matrix," Econometrica, 55, pp.703-708, 1987.

[20] Ng, S. and P. Perron, "Lag length selection and the construction of unit root tests with good size and power," Econometrica, 69(6), pp.15191554, 2001.

[21] Perron, P., "The great crash, the oil price shock and the unit root hypothesis," Econometrica, 57(6), pp.1361-1401, 1989.

[22] Taylor, M. and L. Sarno, "The behavior of real exchanges during the post-Bretton Woods period," Journal of International Economics, 46, pp.281-312, 1998.

[23] Weeken, O., "Asset pricing and the housing market," Bank of England Quarterly Bulletin, 44(1), pp.32-41, 2004. 